\title{
Educación sin república Hitos de la educación peruana en el último siglo
}

Sección ESTUDIOS

RECIBIDO: $10 / 10 / 2020$

APROBADO: $15 / 11 / 2020$

PUBLICADO ONLINE: 18/12/2020

\author{
Teresa Tovar Samanez \\ Pontificia Universidad Católica del Perú \\ teretovarich@gmail.com \\ https://orcid.org/0000-0002-3759-6042
}

\section{RESUMEN}

Retrospectiva de la educación peruana en el último siglo, que distingue cuatro hitos demarcatorios: 1. La educación como privilegio en la sociedad oligárquica; 2 . La crisis del estado oligárquico y un orden nuevo en la educación; 3. La contrarreforma y la mercantilización de la educación y los derechos sociales; y 4. La crisis civilizatoria y el cuestionamiento del modelo educativo neoliberal. El artículo hace una lectura de la relación de la educación con el poder, con la sociedad y con el proceso de transformación del país. A partir de un análisis combinado de cinco componentes, se intenta una interpretación general y articuladora de lo ocurrido en la educación peruana en el último siglo. Estos componentes son: el tiempo político, el rol del Estado, el derecho a la educación y la prioridad de la educación en la agenda. Es posible visualizar los avances y retrocesos de un proceso que no sigue una ruta progresiva constante y que carece de una base institucional y democrática.

PALABRAS CLAVE: educación; derecho; democracia; república; utopía.

\section{Education without a republic Milestones of Peruvian education in the last century}

\begin{abstract}
Retrospective of Peruvian education in the last century, which distinguishes four demarcating milestones: 1 . Education as a privilege in oligarchic society; 2 . The crisis of the oligarchic state and a new order in education; 3 . The counter-reform and the commodification of education and social rights; and 4. The civilizational crisis and the questioning of the neoliberal educational model. The article makes a reading of the relationship of education with power, with society and with the process of transformation of the country. Starting from a combined analysis of five components, a general and articulating interpretation of what happened in Peruvian education in the last century is attempted. These components are: political time, the role of the State, the right to education and the priority of education on the agenda. It is possible to visualize the advances and setbacks of a process that does not follow a constant progressive path and that lacks an institutional and democratic base.
\end{abstract}

KEYWORDS: education; law; democracy; republic; utopia. 


\section{Introducción}

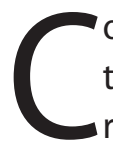

on motivo del próximo bicentenario, resulta pertinente una mirada retrospectiva sobre los principales hitos de la educación peruana. En esta ocasión nos retrotraeremos hasta inicios del siglo XX. Desde entonces hasta el momento actual podemos distinguir cuatro grandes hitos o momentos históricos.

Cada uno de estos cuatro grandes momentos puede ser mejor identificado en sus significados y coordenadas considerando cinco elementos.

1. En primer lugar, es imprescindible tomar en cuenta el sentido de la época, que significa detectar el signo del derrotero histórico de un periodo más o menos prolongado de tiempo. Una época puede tener un signo regresivo o progresivo nuevo, según dé lugar a procesos transformativos o a retrocesos.

2. En segundo lugar, nos interesa ubicar el rol del Estado y de las políticas públicas en la sociedad y frente a la temática de la educación en particular. Éste puede ser fuerte y relacionado al rol de garante de derechos, o débil y precario, donde el Estado juega un rol subsidiario.

3. En tercer lugar, consideremos la dimensión social, que comprende el alcance y situación de los derechos humanos y sociales y la acción de la sociedad civil. El entendido es que la educación es una aspiración social histórica de los pueblos, constituye un derecho humano fundamental y forma parte a la vez de los derechos sociales consagrados o reconocidos en un país.

4. En cuarto lugar, resulta fundamental identificar los sentidos y fines de la educación en cada momento histórico, respondiendo a la pregunta ¿Qué educación propugnamos y para qué tipo de sociedad?

5. Por último, queremos visualizar la presencia y contenido de la agenda social educativa como parte de la agenda política del país.

Mirando en conjunto estos cinco elementos es posible distinguir cuatro momentos históricos entre principios del siglo 20 y el actual siglo 21, visualizando los cambios educativos fundamentales ocurridos en cada uno de ellos. En este sentido, nos preguntamos por la relación de la educación con el poder, la sociedad y la agenda de transformación de nuestro país.

Este esfuerzo de mirar de manera gruesa períodos amplios de tiempo es, sin duda, bastante audaz. Nuestra intención es aportar al debate sobre la encrucijada histórica actual colocando sobre la mesa una interpretación de lo ocurrido. 


\begin{tabular}{|c|c|c|c|c|}
\hline \multirow[t]{2}{*}{ CRITERIOS } & \multicolumn{4}{|c|}{ MOMENTOS HISTÓRICOS } \\
\hline & $\begin{array}{c}1 \\
\text { Sociedad } \\
\text { oligárquica y } \\
\text { exclusión social } \\
\text { y educativa }\end{array}$ & $\begin{array}{l}2 \\
\text { Crisis del Estado } \\
\text { oligárquico y el } \\
\text { orden nuevo en } \\
\text { educación }\end{array}$ & $\begin{array}{c}\text { } 3 \\
\text { Contrarreforma y } \\
\text { mercantilización } \\
\text { de la educación }\end{array}$ & $\begin{array}{c}4 \\
\text { Crisis civilizatoria y } \\
\text { cuestionamiento del } \\
\text { modelo neoliberal }\end{array}$ \\
\hline $\begin{array}{l}\text { El sentido } \\
\text { de la época }\end{array}$ & $\begin{array}{l}\text { Tiempo } \\
\text { regresivo } \\
\text { de un orden } \\
\text { oligárquico }\end{array}$ & $\begin{array}{l}\text { Tiempo } \\
\text { progresivo de } \\
\text { expansión de } \\
\text { derechos y } \\
\text { democracia }\end{array}$ & $\begin{array}{l}\text { Tiempo regresivo } \\
\text { de un orden } \\
\text { neoliberal } \\
\text { que permea y } \\
\text { corrompe la esfera } \\
\text { política }\end{array}$ & $\begin{array}{l}\text { Tiempo de crisis en } \\
\text { el que el viejo orden } \\
\text { neoliberal no acaba } \\
\text { de morir y se junta } \\
\text { a la crisis sanitaria, } \\
\text { social y humanitaria. }\end{array}$ \\
\hline $\begin{array}{l}\text { El rol de } \\
\text { Estado }\end{array}$ & $\begin{array}{l}\text { Estado } \\
\text { excluyente y } \\
\text { autoritario }\end{array}$ & $\begin{array}{l}\text { Modelo de estado } \\
\text { de Bienestar } \\
\text { limitado. Rol del } \\
\text { Estado como } \\
\text { garante del } \\
\text { derecho a la } \\
\text { educación. }\end{array}$ & $\begin{array}{l}\text { Estado subsidiario, } \\
\text { abdica o reduce su } \\
\text { rol de garante de } \\
\text { derechos sociales, } \\
\text { entre ellos la } \\
\text { educación }\end{array}$ & $\begin{array}{l}\text { Reclamos de } \\
\text { políticas de } \\
\text { inversión pública en } \\
\text { salud, educación, } \\
\text { etc. Debate } \\
\text { internacional sobre } \\
\text { a un nuevo tipo de } \\
\text { Estado de Bienestar. }\end{array}$ \\
\hline $\begin{array}{l}\text { Derechos y } \\
\text { aspiraciones } \\
\text { sociales }\end{array}$ & $\begin{array}{l}\text { Negación de } \\
\text { los derechos } \\
\text { humanos y } \\
\text { sociales }\end{array}$ & $\begin{array}{l}\text { La educación es } \\
\text { una aspiración } \\
\text { histórica de los } \\
\text { pueblos y se } \\
\text { afirma derecho } \\
\text { universal y } \\
\text { gratuito. }\end{array}$ & $\begin{array}{l}\text { "Modernidad" } \\
\text { con desigualdad, } \\
\text { exclusión, } \\
\text { violación de } \\
\text { derechos } \\
\text { humanos y } \\
\text { ambientales. La } \\
\text { educación como } \\
\text { mercancía. }\end{array}$ & $\begin{array}{l}\text { Derechos } \\
\text { precarizados y } \\
\text { reducidos versus } \\
\text { emergencia de } \\
\text { una agenda social } \\
\text { que se enfrenta a } \\
\text { intereses de poderes } \\
\text { fácticos. Debilidad } \\
\text { de organización de } \\
\text { la sociedad civil }\end{array}$ \\
\hline $\begin{array}{l}\text { Sentidos y } \\
\text { fines de la } \\
\text { educación }\end{array}$ & $\begin{array}{l}\text { Sentido de la } \\
\text { educación como } \\
\text { privilegio }\end{array}$ & $\begin{array}{l}\text { Sentido de la } \\
\text { educación como } \\
\text { derecho y canal } \\
\text { de movilidad } \\
\text { social } \\
\text { Educación } \\
\text { popular, } \\
\text { educación } \\
\text { liberadora }\end{array}$ & $\begin{array}{l}\text { Se plantea la } \\
\text { calidad educativa } \\
\text { vinculada a la } \\
\text { meritocracia, el } \\
\text { emprendedurismo } \\
\text { y el esfuerzo } \\
\text { individual. }\end{array}$ & $\begin{array}{l}\text { Comienza una } \\
\text { disputa de sentidos } \\
\text { en la educación: } \\
\text { los conservadores } \\
\text { versus los que } \\
\text { proponen como } \\
\text { eje la igualdad y la } \\
\text { justicia }\end{array}$ \\
\hline $\begin{array}{l}\text { Agenda } \\
\text { educativa } \\
\text { y agenda } \\
\text { nacional }\end{array}$ & $\begin{array}{l}\text { La educación } \\
\text { es parte de } \\
\text { la agenda } \\
\text { nacional de } \\
\text { cuestionamiento } \\
\text { del orden } \\
\text { excluyente }\end{array}$ & $\begin{array}{l}\text { Convergencia } \\
\text { entre la } \\
\text { agenda de } \\
\text { universalización } \\
\text { del acceso a la } \\
\text { educación con la } \\
\text { agenda nacional. }\end{array}$ & $\begin{array}{l}\text { La agenda } \\
\text { educativa oficial } \\
\text { se restringe a la } \\
\text { administración } \\
\text { de la precariedad } \\
\text { educativa y se } \\
\text { distancia de la } \\
\text { agenda educativa } \\
\text { social }\end{array}$ & $\begin{array}{l}\text { La agenda educativa } \\
\text { se junta a la agenda } \\
\text { social en medio } \\
\text { discusión de la } \\
\text { "nueva normalidad" }\end{array}$ \\
\hline
\end{tabular}




\section{Primer momento.}

\section{La sociedad oligárquica y la exclusión social y educativa}

Tiempo regresivo donde impera un orden oligárquico, con un Estado excluyente y autoritario y una situación de negación de los derechos humanos y sociales básicos. El sentido de la educación es el de ser un privilegio de las élites. Se inicia el cuestionamiento de este orden excluyente y la educación es parte constitutiva de esta agenda nacional.

A principios del siglo pasado existía lo que se ha denominado como Estado Oligárquico. Se trataba de un orden social excluyente, donde una minoría concentraba el poder económico y político y lo ejercía en forma autoritaria. El Estado como aparato institucional era reducido. Se trataba de un tiempo regresivo, donde el "Estado Imperium" imponía su poder y dominio por la fuerza y representaba los intereses de los sectores oligárquicos, dueños de los grandes latifundios. Estos intereses eran cristalizados en privilegios y prebendas que se imponían mediante un régimen de sujeción a los campesinos.

En este orden excluyente la población campesina e indígena no tenía lugar ni reconocimiento. Es por ello que José Carlos Mariátegui planteó como asunto central la cuestión agraria y, con ella, la situación del indio. Esto implicaba terminar con el régimen de servidumbre en los latifundios. Resultaba contradictorio plantear una República con la persistencia de masas indígenas dominadas, humilladas y casi esclavizadas.

La educación y los derechos sociales estaban restringidos a las élites y no conformaban parte de la ciudadanía ni de la promesa republicana. La filosofía educativa que estuvo en el discurso de la independencia no tenía un correlato en la realidad social. Con la instalación de la república las personas adquirieron tan sólo una ciudadanía formal ya que supervivieron las formas de vida colonial, la esclavitud del negro y la servidumbre del indio. La promesa republicana existía solo en un plano declarativo de ya que el Perú estaba organizado jerárquicamente en un rígido sistema de estratos sociales (Neira 2019: 2). La educación seguía constituyendo un privilegio de castas y el racismo era parte de la cultura hegemónica. (Tovar 1994:54).

Para Mariátegui el problema de la educación estaba íntimamente vinculado al del "problema del indio". Señalaba que existe un "íntimo engranaje entre la economía y la enseñanza" (Mariátegui 1979: 32). La educación era parte de las aspiraciones sociales de inclusión, parte de los derechos negados por la oligarquía. "No nos contentamos con reivindicar el derecho del indio a la educación, a la 
cultura, al progreso, al amor y al cielo. Comenzamos por reivindicar, categóricamente, su derecho a la tierra." (Mariátegui 1929: 50).

Los fines de la educación estaban limitados a la ilustración de la élite gobernante. No guardaban ninguna relación o correspondencia con la construcción de un sentido de pertenencia igualitaria al país. Por el contrario, se enseñaba a aceptar como natural la existencia de enormes mayorías sin derechos, excluidas y despreciadas por las élites.

La educación nacional, por consiguiente, no tiene un espíritu nacional: tiene más bien un espíritu colonial y colonizador. Cuando en sus programas de instrucción pública el Estado se refiere a los indios, no se refiere a ellos como a peruanos iguales a todos los demás. Los considera como una raza inferior. La República no se diferencia en este terreno del Virreinato. (Mariátegui 1929: 49)

En este contexto, en el caso educativo, se produce la memorable polémica Deústua/ Villarán. Alejandro Deústua concebía a los indígenas como animales o seres sin alma, negando su posibilidad de entendimiento. Villarán en cambio reclamaba la formación de seres humanos útiles, creadores de riqueza, y reclamaba poner fin al analfabetismo. El primero representaba el pensamiento conservador y el segundo el pensamiento afín a la modernización.

Muchos de los legados culturales de la época oligárquica persisten hasta hoy. Seguimos siendo una sociedad fuertemente estratificada, segmentada y racista, donde las prebendas y privilegios persisten y son acompañadas por fuertes estereotipos y prejuicios. Este orden se expresó de manera "legal" en normativas que distribuyen derechos y oportunidades de manera desigual a lo largo de décadas. Aún en la actualidad, siguen existiendo "dueños del Perú", organizados como una red de contactos, alianzas y privilegios que resguardan la concentración económica desmesurada y una desigualdad social obscena (Durand 2004).

Hugo Neira señala que lo que existía y persistía en la época contemporánea es el despotismo. La oligarquía no había muerto en el pensamiento de las élites y esto significaba que las normas legales que se suponían regían nuestra república eran tan sólo una fantasía:

Un día en París, en el hall de Sciences, mi profesor y amigo François Bourricaud, que tan finamente describe la sociedad peruana en sus obras, me pega un jalón, y sabiendo que volvía al Perú después de mi tesis francesa, me dice:"No se olvide usted Neira, ustedes acabaron con la oligarquía, pero no con el hombre oligárquico". ¿No es acaso el tejido despótico la realidad y no la ilusión de la norma igualitaria? (Neira 2019: 2). 
El Estado Oligárquico hace crisis en los años 30. En el Perú de 1930 convergen la crisis del orden oligárquico y la crisis de la educación elitista y excluyente. La emergencia de un nuevo orden republicano requería la inclusión de vastos sectores de la población cuya condición humana y ciudadana había venido siendo negada durante siglos. La reforma de la educación estaba en el corazón de la agenda de desarrollo.

\section{Segundo momento.}

La crisis del Estado oligárquico y el orden nuevo en educación

Es un tiempo progresivo de expansión de derechos y de la democracia que forma parte de un modelo de Estado de Bienestar que llegó algo tarde y con límites a nuestro país. Aparece el rol del Estado como garante del derecho a la educación y la educación se concibe y formula como una aspiración histórica y legítima de los pueblos, afirmándose como derecho universal y gratuito y canal de movilidad social. Se produce la convergencia entre la agenda de universalización del acceso a la educación con la agenda nacional de modernización, industrialización y democracia. Emergen los enfoques de educación popular y educación liberadora.

Con la crisis del Estado el oligárquico en la década del 30 se inicia una etapa de signo progresivo en la historia del país. En ella la inclusión social estaba planteada al mismo tiempo que la instauración de un Estado de derecho y el fin de una sociedad de privilegios.

Tuvimos que aguardar casi medio siglo para que la crisis del orden oligárquico tuviera fin. La estocada final al mismo constituyó sin duda la Reforma agraria del gobierno militar de Juan Velasco Alvarado que terminó con el oprobio de los gamonales y con la servidumbre de los indígenas La frase "el patrón no comerá más de tu pobreza", eslogan de la Reforma Agraria, se perennizó. Junto a ella apareció la Reforma de la Educación más importante del siglo XX (Tovar 2019).

La reforma educativa de Velasco cristaliza un proceso de varias décadas. Ya desde los años 50 en adelante, la educación se había instalado como aspiración social fuerte, siendo visualizada como "la mejor herencia", aquella que los padres aspiraba a dejar a sus hijos. Sucedía que la utopía de la inclusión coincidía con el cambio del paradigma de desarrollo, y la educación era parte sustancial de ambos: el acceso a la educación era una vía central para la incorporación en condiciones menos desiguales a la sociedad peruana y a las oportunidades que se abrían. La promesa republicana se dibujaba en el horizonte como una posibilidad. 
Durante los años 50 y 60 se registran intentos del Estado por fortalecerse y ampliar su injerencia en la cuestión social. Se instala, con límites, un modelo de Estado de Bienestar, con mayor prioridad y recursos para educación vinculado al proceso restringido de industrialización que tuvimos en nuestro país. Se dieron políticas limitadas de sustitución de importaciones, programas sociales, etc. que se plasmaron en un aparato estatal que creció y se modernizó. Comienza a incrementarse el acceso a la educación y ésta pasó a acompañar el desarrollo y a formar parte de las políticas y la intencionalidad pública.

En otras palabras, «educación y progreso» iban juntos en la visión de país. La educación se planteaba como un derecho social que se ampliaba junto con otros como la salud y el trabajo en el marco de un momento de crecimiento económico. Aparecía en el sentido común de las grandes mayorías como aspiración. La utopía del progreso coincidía con la utopía republicana y con el planteamiento de la educación como canal de inclusión y movilidad social.

Cuarenta años después de la crisis del 30 se produce el cambio educativo más importante del siglo XX: la reforma educativa del 70, impulsada por Velasco Alvarado, (Ley General de Educación No.19326, el 21 de marzo de 1972). Esta reforma acumuló los cambios anteriores y concretó el sentido progresivo de la época en el campo la educación. La convergencia entre la agenda educativa y la agenda social la inclusión se expresó en la coincidencia de la reforma educativa de Velasco con la instauración por primera vez el voto para el analfabeto. Educación y ciudadanía iban de la mano en el imaginario de país.

Una Comisión integrada por reconocidos intelectuales (Emilio Barrantes, Walter Peñaloza y Augusto Salazar Bondy) elaboró sus fundamentos, que se plasmaron en el famoso Libro Azul ("La educación del hombre nuevo. La Reforma educativa peruana") y en una Ley de Educación.

El objetivo era construir "un hombre nuevo para una sociedad nueva". La reforma educativa era parte de la transformación del país e involucró un cambio total de la educación, desde sus enfoques hasta sus diversos componentes, estructuras y procesos.

El signo más importante de estos cambios fue la igualdad, comenzando por el acceso a un derecho escamoteado durante siglos. En el Informe general de la Reforma se da cuenta de la expansión del acceso a la educación. "En 10 años (1958-1968) la población escolar matriculada aumentó casi en 100\%" (Comisión de Reforma de la Educación 1970: 15) y el porcentaje de estudiantes matriculados pasó de $40.6 \%$ en 1960 al $73.8 \%$ en 1980 (Degregori, 1989: 15). 
La inversión en educación fue de la mano con el impulso la reforma. Entre los años 50 y 70 crece sostenidamente la inversión por alumno expresada en gasto público por estudiante y $\mathrm{PBI}$ por habitante El primero se triplica y el segundo se duplica. A partir de los años 70 empieza una caída constante del gasto en educación. (Guadalupe, Twanama y Castro, 2018: 25, Miranda y Pacheco 2020: 10).

En concordancia con el tiempo progresivo de la época que daba término al orden de servidumbre, se planteó la universalización de la educación y se abrieron oportunidades para que vastos sectores de la población accedieran a la educación. Se produce una convergencia entre la agenda de acceso universal a la educación con la agenda nacional. El sentido general de la educación era la aspiración de educación gratuita para todos y en torno a ello se articula la gestión de las políticas públicas que afirmaron el rol del Estado como garante de este derecho.

El Plan Educativo Nacional 1971-1975 que acompañó la reforma tuvo como lineamientos la erradicación total del analfabetismo, brindar efectiva igualdad de oportunidades, llegar a todos los peruanos, ofrecer escolaridad básica, efectiva y diversificada para toda la población (pág. 146). El signo de igualdad tuvo una expresión simbólica importante en la reivindicación del idioma quechua, la puesta en valor de la cultura andina, la erradicación de diferencias en la vestimenta de los estudiantes.

Pudimos verlo en aspectos muy concretos como el uniforme único, que los colegios privados tuvieron que aceptar a regañadientes. Ya no era posible distinguir en la calle a un estudiante de una Gran Unidad escolar de uno de un colegio privado como el Humboldt. El gobierno declaró el quechua como idioma oficial e instituyó la educación bilingüe como parte de la reivindicación de la dignidad de la población indígena, que también se afirmó mediante el programa de alfabetización ALFIN. En el plano cultural el huayno y la música afroperuana, que antes eran motivo de vergüenza, ingresaron a las fiestas y a las escuelas, y allí se quedaron. (Tovar 2019)

La transformación educativa estaba fuertemente vinculada a la transformación cultural, a lo que Gramsci denomina reforma intelectual y moral.

La utopía de la inclusión coincidía con el cambio del paradigma de desarrollo y la educación era parte esencial de ambos. Esto suponía el impulso a la educación pública. Cobraron vigencia los planteamientos de Mariátegui. "La idea de la escuela pública aparece consustancial y solidaria a la idea de una democracia social. La idea democrática no permite mantener en la sociedad compartimentos estancos, castas. Los individuos son libres e iguales y tienen el mismo derecho a desarrollase mediante la cultura" (Mariátegui 1970: 42). 
Es desde el Estado, desde la esfera pública, que se propugna la universalización del derecho a la educación. El rol del Estado educación es central: se asigna al Estado la responsabilidad de ser el garante del acceso a la educación y del ejercicio de este derecho. Esto implicaba que el Estado debía proveer oportunidades de educación para todos vía la instauración de políticas universales y del reconocimiento de derechos entre ellos el derecho de educación como parte de la ciudadanía.

Otra finalidad de la educación propuesta por la reforma de Velasco fue la formación de capacidades y destrezas para la incorporación de las personas a las nuevas oportunidades y de trabajo. El lema educación para el trabajo de la reforma del 70 sintetiza esta meta. Para concretar el vínculo entre educación y proceso productivo se creó la Educación Básica Laboral (EBL) como opción a la Educación Básica Regular. La EBL apuntaba a formar carreras y oficios técnicos (mecánica, carpintería, zootecnia, avicultura, etc.). Asimismo, se impulsó las Escuelas Superiores de Educación Profesional-ESEP, una modalidad deformación pre-universitaria vinculada a una proyección laboral.

Los avances en la economía iban de la mano con logros en la democracia. Se amplió la esfera y ejercicio de derechos sociales y, además, se dio cabida a los movimientos e institucionalidad de las clases pobres y trabajadoras. Los sindicatos, comunidades campesinas, asociaciones de pueblos jóvenes, organizaciones de artesanos, etc. se fortalecieron y jugaron un rol social en pro de la ampliación de derechos y oportunidades, entre ellos la educación. Asimismo, se desarrollaron procesos de concientización y politización dentro de capas de los sectores sociales organizados.

En el debate pedagógico internacional cobraron vigencia los planteamientos de Paulo Freire y la educación liberadora, que proponían una educación concientizadora y desalienante. Ello tuvo algunos puentes con la llamada teología de la liberación y con la propia reforma educativa, que planteaba como uno de sus aspectos a educación crítica. El Libro Azul planteaba que la educación debía tener un signo de "desalienación", que desde un enfoque humanista hiciera posible la recuperación de la dignidad de todos los seres humanos y provocara "una alteración substancial de la cultura de dominación" (Bondy 1975: 9).

La idea central de la ley inspirada en los escritos de Augusto Salazar Bondy concebía a la educación como generadora de una consciencia crítica de la realidad y promotora de la transformación de las relaciones de dominación que caracterizaba a la sociedad peruana. Esto tenía cabida en el planteamiento general del velasquismo: para Velasco la agenda educativa contribuía y era parte sustancial de 
la transformación de la sociedad y por ello la reforma educativa planteó y promovió el nexo entre educación y transformación global de la sociedad.

El signo transformador expresado en lo que se denominó promoción de la "conciencia crítica" convergía con el enfoque de Freire, para quien la educación debía ser problematizadora y liberadora y partir de una visión crítica del mundo. "en la realidad, de la que dependemos, en la conciencia que de ella tengamos educadores y pueblo, buscaremos el contenido programático de la educación. El momento de esta búsqueda es lo que instaura el diálogo de la educación como práctica de la libertad" (Freire 1970: 79).

En distintos espacios del Estado y la sociedad civil, ONG, se formaron maestros y educadores bajo el enfoque freiriano. Se gestó un movimiento pedagógico que construyó escuelas y desarrolló lo que se llamó la "educación popular", conectada, a su vez, con los planteamientos sobre la misma a nivel de América Latina.

Muchos de estos educadores participaron del impulso a la reforma educativa de Velasco. Esto era posible porque dicha reforma tuvo como uno de sus aspectos más importantes la priorización de la relación entre educación, contexto y comunidad. La reforma posibilitó la participación a la comunidad en la educación, incluyendo la intervención organizada de las familias y la población vía los Núcleos Educativos Comunales. Estos buscaban vincular la escuela con la vida de la población, recuperando la tradición de cooperación campesina y rompiendo con el esquema de la escuela ajena, cerrada y remota.

Se abrieron distintas posibilidades de inclusión educativa y de educación crítica en las diversas modalidades educativas abiertas por la Reforma. Comenzando por la alfabetización y la educación de adultos, fuertemente inspirada en los planteamientos de Freire, incluyendo también los programas educativos para áreas rurales y la educación comunitaria.

La reforma educativa del 70 trascendió su tiempo. Su significado y alcances no se percibieron en lo inmediato y sólo fueron reconocidos a cabalidad décadas después. Se trató de una reforma fuertemente criticada y denostada, sobre todo por los sectores conservadores, que finalmente lograron revertirla. "durante dos gobiernos sucesivos, o sea durante diez años, esta Reforma fue, en gran parte, destruida". (Palomino Thompson 1993: 113). Sobrevino la contrarreforma (Ley 23384 de 1982) de los gobiernos de Morales Bermúdez (1975-1980) y Belaunde Terry (1980-1985), que vuelve al sistema educativo anterior. Esta contrarreforma terminó con los signos "radicales" de Velasco. El cuento Paco Yunque fue retirado

1 Este cuento muestra la humillación y vejámenes que Humberto Grieve, hijo del gerente inglés de los ferrocarriles de la Peruvian Corporation, ocasiona a Paco, hijo de la empleada doméstica de su casa. 
de los materiales educativos, se anuló la obligación de usar el uniforme único y se retornó a la vieja estructura: inicial-primaria-secundaria-superior.

Algunos cambios trascendieron. Destaca la educación bilingüe y la reivindicación de la diversidad cultural, que hoy se expresan en la educación bilingüe intercultural como política nacional. La flexibilidad del sistema educativo inaugurada por la reforma fue rescatada por La Ley de Educación del 2003. Pero hay mucho más que reivindicar, pues varios de sus aportes y potencial se han debilitado o desdibujado, como el vínculo escuela-comunidad, el sentido crítico y emancipatorio de la educación y la fuerza de la educación permanente en todos los espacios de la vida. Asimismo, se formaron generaciones de educadores, mucho de los cuales siguen vigentes en la actualidad en distintas esferas de la sociedad y el Estado. Varios de ellos impulsaron importantes documentos de consenso nacional que poseían el aliento y orientación de planteamientos de la reforma de Velasco. Así años después, se concretaron documentos de importancia en materia educativa como la Política No. 12 del Acuerdo Nacional (2002), la nueva Ley de Educación de 1983 y en el Proyecto Educativo Nacional 2007-2021.

\section{Tercer momento. Tiempo regresivo de contrarreforma y mercantilización}

Se trata de un tiempo regresivo donde se instala un orden neoliberal en el que el Estado tiene un rol subsidiario y reduce su rol de garante de derechos, entre ellos la educación. Regresa la desigualdad y exclusión en el contexto de modernización y globalización, que incluyen la violación de derechos humanos y la indiferencia frente a la crisis climática y ambiental. La educación se configura como mercancía y se instala un sentido de prosperidad individualista vinculado a la meritocracia, el emprendedurismo y el esfuerzo individual. La gestión de política públicas se encamina a administrar la austeridad fiscal y la precariedad de la educación pública, monitoreando el cumplimiento de metas de eficiencia. La agenda educativa oficial se distancia de la agenda educativa social, mientras que el movimiento social se debilita.

Este período está comprendido entre los años 80 del siglo pasado y lo que va del presente siglo y se produce luego de la clausura del modelo de crecimiento hacia adentro. Se instauraron cuatro largas décadas que, a su vez, comprendieron dos fases: Una de recesión económica que denominó a la década 80-90 como "la década perdida", y otra fase de crecimiento económico sustentado básicamente en las exportaciones de minerales (2000-2015) que se dio dentro "la vuelta a la 
aplicación de medidas económicas a favor del modelo primario-exportador" (Miranda, Pacheco 2020:60).

En una economía que se contraía y que constreñía las políticas sociales, la educación dejó de formar parte del movimiento de inclusión y las políticas sociales adelgazadas desdibujaron lo avanzado en términos de orden republicano. Esta lógica prosiguió luego de superada la recesión, estableciéndose una distancia entre la implantación exitosa del proyecto neoliberal y "el fracaso del proyecto republicano". (Vergara 2018:13).

Se instauró una nueva utopía donde la magia del mercado se entroniza y es vista como el eje ordenador que puede prescindir o achicar las instituciones y el Estado de Derecho. Ello trajo varias consecuencias para la educación.

La educación como política pública se desdibujó fuertemente Es el fin del Estado de Bienestar. El Estado se reduce, pasándose a entender la inversión social como gasto y diluyéndose el lugar e importancia de la educación pública. Las mismas tendencias en lo educativo se registran tanto en la época de las vacas flacas como en la de las vacas gordas, de modo que pese a tener cifras espectaculares de crecimiento del PBI en la etapa 2000-2010, la educación pública se precariza progresivamente. Incluso en el momento 2000-2015, las altas tasas de crecimiento económico convivieron con baja inversión pública en educación (Miranda, Pacheco 2020: 62).

Las deficiencias de la educación pública se acumulan y no hay presupuesto asignado para hacerles frente. La brecha acumulada de infraestructura en la educación pública sobrepasa hoy los 100 millones de soles. En el Perú hay 62 mil escuelas públicas, de las cuales más de la mitad no cuentan con servicios básicos de agua, desagüe y luz. Lo que había ocurrido es que la educación dejó de integrar la agenda política prioritaria, arrimada a un costado en presupuesto, importancia y voluntad política, en medio del achicamiento del Estado en términos de rol y responsabilidades. La educación no pudo mantenerse ajena al devenir de la economía y del modelo de capitalismo primario exportador, extractivista, que privilegia el lucro y la concentración de ingresos en los sectores más pudientes y posterga la inversión en lo social.

La matrícula estatal se incrementa al ritmo del incremento poblacional, pero esto contrasta con la caída de la inversión por estudiante (Guadalupe, Twanama y Castro, 2018:25, Miranda y Pacheco 2020: 11), es decir hay pocos e insuficientes recursos para atender a más estudiantes.

Se privilegia las políticas focalizadas por sobre las universales. En el caso educativo, el programa Beca 18 favorece a un aproximado de seis mil estudiantes, con 
educación gratuita, recursos y condiciones de calidad y financiación a los estudiantes, contrastando con los cerca de dos millones de alumnos de educación superior pública que estudian en condiciones precarias y con maestros mal pagados ${ }^{2}$. De manera similar los COAR, Colegios de Alto Rendimiento ofrecen educación pública con alta inversión por estudiante a una minoría ( $1 \%$ de estudiantes recibe 13 veces más que la inversión por estudiante de un colegio público, Bello 2018:35). Estudiar con calidad y en buenas condiciones deja de ser un derecho para convertirse en una lotería. Las políticas focalizadas dejan de ser un complemento a las políticas universales que devienen en secundarias.

Se abre el mercado de la educación. Con respaldo legal en la Constitución y en el DL 882 que permite el lucro ${ }^{3}$, la educación deviene en un servicio que se compra y se vende, cuya calidad depende de lo que se pueda pagar por él. Proliferan escuelas, institutos y universidades de bajo costo y calidad educativas de bajo costo y baja calidad, produciéndose un proceso silencioso y persistente de privatización "por default". Este fenómeno y el incremento de la oferta privada están ampliamente documentados y alcanzan el 50\% en Lima y el $30 \%$ a nivel racional (Balarín 2016).

La inclusión educativa se detuvo por la fuerza segregadora del mercado. La mercantilización de la educación segmenta y dibuja una ruta de desigualdad donde los más pobres y discriminados salen perdiendo. Se profundiza la brecha entre una educación precaria para las grandes mayorías y otra educación de alta paga para las élites del país. Los sectores pobres acceden, o bien a una educación pública precaria, o a una educación privada deficiente. Por ello, incluso las altas tasas de crecimiento del PBI país conviven con situaciones graves de desigualdad. Son los estratos socioeconómicos más bajos los que registran mayor pobreza y desigualdad educativa (Cuenca 2019).

Los COAR constituyen un caso especial de segregación, pues se hace con fondos públicos y viola derechos y compromisos respaldados por la normativa internacional. Esta transgresión de derechos se da en dos sentidos: en términos de inclusión educativa, que debe dar atención especializada en entornos integrados e inclusivos y, en términos de asignación diferenciada de fondos públicos que sólo se justificaría para compensar inequidades para los más vulnerables. Los COAR atienden "a estudiantes de estratos económicos más altos entre los que asisten a instituciones educativas públicas" y la condición de pobreza no es un requisito para postular a ellos. (Bello 2018:33).

2 Adicionalmente, Beca 18 posibilita la financiación de instituciones privadas con recursos públicos.

3 EI DS 082 dado por Fujimori que permite la educación-estafa-negocio-redondo no sólo no ha sido derogado, sino que incluso hay presiones para mantenerlo. 
En conjunto se desdibuja el sentido de la educación como derecho. SI nos remontamos un poco en la historia, podemos concluir que la ecuación crecimiento económico con equidad y educación, hija del paradigma de la Comisión Económica para América Latina y el Caribe (Cepal), no llegó a funcionar nunca en nuestro país. No hubo crecimiento económico con equidad, sino que, por el contrario, lo que se dio durante casi 40 años fue crecimiento económico con inequidad.

Todos estos cambios tuvieron un correlato en el pensamiento educacional instalando de una manera distinta de entender y gestionar la educación. Bajo la influencia de organismos como el Banco Mundial se refuerza la visión del Estado mínimo como ideal y se promociona el aporte y esfuerzo de las comunidades a la vez que se responsabiliza a las personas de salir adelante y superar sus condiciones de pobreza. En lugar de proponer políticas para cerrar las brechas de desigualdad y terminar con la segregación, las políticas que impulsa el Banco se dirigen centralmente a modificar la conducta de los seres humanos, para que tomen mejores decisiones en relación a sus costumbres y hábitos (Tovar 2020b:2).

"Con pequeñas modificaciones en el contexto en que se toman las decisiones, con iniciativas diseñadas a partir de la comprensión de las preferencias sociales y con la exposición de los individuos a nuevas experiencias y nuevos modos de pensar, se puede lograr que las personas mejoren su calidad de vida"(BANCO MUNDIAL b:38).

Es decir, se propugna una visión individualista de progreso y se evita hablar de derechos y de políticas universales. No olvidemos que un "leitmotiv" de las élites de poder es flexibilizar las condiciones de trabajo, legalizar despidos, y estimular la competencia salvaje para la sobrevivencia. La educación no escapa a esta lógica y en ella se instala también la competencia.

Las palabras cambian, trastocando los sentidos fundamentales. En lugar de derechos se habla de servicios, en vez de desigualdad se habla de pobreza y se sustituye la precariedad de las políticas educativas por la "pobreza de los aprendizajes". Es decir, incluso las deficiencias de las políticas públicas serían superadas, en esta visión, por esfuerzos individuales y por la disposición emocional de las personas

"El Banco Mundial ha planteado como problema la"pobreza de los aprendizajes". Estamos ante una nueva nomenclatura que oculta los problemas de fondo: la desigualdad social, racial, cultural, de género. Al igual que las "habilidades emocionales" (otro nuevo "concepto") pretende adjudicar a las personas la responsabilidad de superar su pobreza, obviando o minimizando las responsabilidades del Estado de garantizar condiciones de educabilidad iguales para todos y de proveer los recur- 
sos para compensar las desigualdades por razón de cultura, etnia, género, edad o discapacidad" (Tovar 2020 b: 1).

La mención de "habilidades socioemocionales" es controversial. No se plantea como parte de la construcción de la autonomía y la personalidad moral de las que nos habla Adela Cortina. Tampoco se la asume en el sentido de la "inteligencia emocional" formulada por Daniel Goleman. Lo que se está proponiendo es moldear emocionalmente la conducta de los sectores populares, para que superen su "pobreza cognitiva", se busquen sus propias oportunidades y así dejen de ser pobres, ahorrando de paso costos al Estado (Tovar 2020 b: 1).

Simultáneamente se propugna un enfoque restringido de calidad educativa. Se ha venido implementando un modelo centrado en los desempeños de maestros y alumnos, enlazados a un sistema de evaluaciones continuas de habilidades básicas en matemáticas y comunicación, con referentes estandarizados de "logros de aprendizaje", para lo cual se implementa un sistema de monitoreo y evaluación con rutas, rúbricas y supervisión.

Se trata de un modelo que comienza a ser puesto en cuestión en otros países ya que estrecha la formación integral y convierte a los docentes en implementadores instrumentalizados de pruebas. La excesiva presión evaluativa termina ahogando las iniciativas y motivación de escuelas, docentes y estudiantes y tiende a sustituir el fin (las personas) con el medio (los aprendizajes y desempeños). En la práctica se ha cambiado la calidad de la educación por eficiencia, entendiéndola como rendimiento escolar en sólo dos asignaturas.

Esto se acompaña con el llamado modelo meritocrático que tiene detrás un mito hoy rebatido: "si trabaja y tiene talento, cualquiera puede ascender socialmente" (Sandel 2020). La meritocracia sólo funciona cuando hay condiciones de igualdad y justicia. Y en el Perú tenemos todo lo contrario. Cuando la meritocracia se instala sobre condiciones de desigualdad no atendidas o insuficientemente atendidas, se transforma en una carrera injusta.

Hoy este discurso meritocrático se instala sobre la creciente desigualdad, y produce un efecto contrario porque produce ganadores y perdedores, a la vez que alimenta la ira y la frustración (Sandel 2020). Según Piketty el gran relato liberal que gira en torno a la idea de la «meritocracia» es falso y hoy muy pocos creen que la pobreza se debe a la falta de ambición o de esfuerzo (Piketty 2019: 1135).

"La reforma educativa neoliberal meritocrática. El discurso meritocrático tiene por objeto ensalzar a los ganadores y estigmatizar a los perdedores del sistema económico por su supuesta falta de mérito, talento y diligencia. Es, por supuesto, 
una ideología antigua a la que todas las élites han recurrido de una manera u otra para justificar su posición, en cualquier época y lugar". (Piketty 2019: 848).

Se produce una "colonización de la subjetividad" (Merlin 2017) que manipula simbólicamente el imaginario social, mediante una batalla cultural desigual.

La competencia se asume como natural, se impulsa el esfuerzo individual y se diluyen las formas colectivas de construir conocimientos. La idea de la escuela como comunidad de aprendizajes y del trabajo de equipo entre los docentes ${ }^{4}$ ya no encuentran sitio. La meritocracia, se asume como "principio", cuando es en realidad un criterio para clasificar, evaluar y/o jerarquizar a las personas según su esfuerzo y su talento individuales, al margen de la clase social a la que pertenecen, el género, la etnia, la edad o las diferencias de talento o capacidad.

Este nuevo discurso contradice en muchos de sus postulados los enfoques consensuados en el período anterior. Como efecto de la crisis del Estado Oligárquico, se habían concretado un conjunto de planteamientos generales progresivos en educación. Muchos de ellos ya no encuentran lugar y acogida.

Este tercer período de contrarreforma y mercantilización contiene una paradoja: desde fines del siglo XX educación, derechos sociales y ciudadanía estaban en el imaginario educativo expresado en instrumentos nacionales como la Ley General de Educación del 2003 y el Proyecto Educativo Nacional al 2021, pero, aunque existía una utopía en educación, la educación no era ya parte de la utopía del desarrollo neoliberal. La divergencia entre imaginario educativo incluyente y modelo económico excluyente se impuso y terminó convirtiendo la utopía incluyente en discurso vacío.

En lugar de la agenda fundamental que planteaba colocar al centro la finalidad de la tarea educativa: el desarrollo humano pleno y el sentido crítico y emancipatorio de la educación aunado a una expansión de derechos, libertades y capacidades; se planteó una agenda tecnocrática de búsqueda de la eficiencia pese a la desigualdad, agenda que, en el mejor de los casos, sólo llega a los tobillos de la agenda nodal transformadora.

La lógica predominante de esta etapa fue regresiva. Educación y modelo de desarrollo volvieron a ir juntos, pero ya no en un sentido de expansión de derechos y ciudadanía, sino en un sentido de constricción de derechos y entronización de modos de pensar afines al individualismo, la competencia y la segregación.

La imposición del modelo educativo de mercado no ocurre en un terreno plano o vacío, sino en uno de disputa. Por un lado, arrecian las voces ultra conservadoras

$4 \quad$ Establecida en la Ley General de Educación del 2003 
que se expresaron en el movimiento conmishijosnotemetas, y la defensa de las instituciones educativas de lucro. Por otro lado, los poderes fácticos presionaban el recorte del presupuesto público y la desatención de los sectores vulnerables, de modo que las poblaciones rurales, los pueblos originarios, las personas con discapacidad, los jóvenes y adultos fueron crecientemente marginalizados y desatendidos.

Muchas de las batallas conservadoras fueron impulsadas cercanas o de la mano con la corrupción. Por casi décadas, tuvimos como contexto un sistema de corrupción que efectuó simultáneamente la mercantilización de lo público y el saqueo del Estado.

Pero, además, la disputa incluyó iniciativas de resistencia progresiva desarrolladas en diversos espacios del esto, la sociedad civil y la cooperación. El movimiento magisterial presentó una resistencia reivindicativa frente al recorte de sus derechos en un marco donde las organizaciones sociales habían sido fuertemente debilitadas e incluso desmanteladas. Sus reclamos incluían la formación docente (donde el Estado acumuló una enorme deuda con los maestros), la reducción del número de maestros contratados, la promoción social y el respeto irrestricto a la dignidad profesional del docente. "Mi nombre es maestro, mi apellido es dignidad" rezaba un cartel de la huelga del 2017.

Hubo algunos otros movimientos sociales como el de los jóvenes contra la llamada "Ley Pulpín" que recortaba derechos, las luchas de pueblos indígenas en defensa de sus territorios y patrimonios, los colectivos en contra de la corrupción, las iniciativas en favor de la igualdad de género. No obstante, no lograron articularse en un movimiento ciudadano. Eran esfuerzos que venían de una situación de desventaja el nuevo modelo de "desarrollo" se dio junto a un debilitamiento de la institucionalidad social y democrática en el país.

También fueron importantes las iniciativas de regulación de la oferta privada en educación tanto a nivel de la educación superior (Ley Universitaria y SUNEDU) como de la educación básica (DU 002-2020), que desataron la oposición de sectores con intereses de negocio en instituciones educativas. La regulación de la oferta privada no significa el impulso y fortalecimiento de la oferta pública, ni tampoco el fin del lucro en la educación.

Desde el Estado, algunas gestiones impulsaron medidas de regulación de la calidad de la oferta privada, desatando la ira de los dueños de los negocios educativos. Destacó también la defensa del enfoque de igualdad de género, al principio tímida pero luego decidida. Particularmente importante fue el impulso de la educación intercultural bilingüe que logró ser formulado como planteamiento real y eficaz y consiguió la asignación de recursos. Asimismo, se logró un consenso sobre 
la priorización de la educación y atención a la primera infancia, ésta última desde una acción intersectorial.

La cooperación y las ONG impulsaron estos y otros cambios, algunos con menor éxito. La educación ambiental, la educación comunitaria, la educación inclusiva para estudiantes con discapacidad, la educación de jóvenes y adultos y la educación ciudadana, quedaron en un lugar secundario y marginal. Algunos de estos aspectos lograron espacio en el discurso oficial pero no consiguieron recursos ni medidas consistentes.

En la década de 1990 y en lo que va de este siglo, los esfuerzos para impulsar la educación como ejercicio de derechos y como canal de integración e igualación social se emprenden, entonces, desde los márgenes de la sociedad y la política, con presupuestos recortados, con propuestas trabajadas por la sociedad civil, tratando de incidir en las políticas públicas. Estos esfuerzos avanzan un poco cuando se cierra la dictadura de Fujimori pero no logran darle la vuelta al modelo segregador.

En suma, hemos tenido una "inclusión" educativa excluyente. Todos sus componentes: información, decisiones, condiciones materiales de aprendizaje, calidad de docentes y procesos pedagógicos, resultados educativos, prestigio de las IIEE, reconocimiento de derechos ciudadanos, respeto a los derechos humanos y la dignidad, están hoy polarizadamente distribuidos en nuestra sociedad

Las políticas que apostaron por la educación pública no pudieron contrarrestar su precarización. El equilibrio macroeconómico logrado convivió con una situación de hecho: la educación es hoy un derecho que no se cumple a plenitud.

\section{Cuarto momento.}

\section{Crisis civilizatoria y cuestionamiento del modelo educativo neoliberal}

Tiempo de crisis en el que el viejo orden neoliberal no acaba de morir y se junta a la crisis sanitaria, social y humanitaria. Emerge un debate internacional sobre un nuevo tipo de Estado de Bienestar que requiere políticas de inversión pública en salud, educación, etc. Se parte de una situación de derechos precarizados y reducidos que está dando lugar a la emergencia de una agenda social que tiene como eje nodal la justicia y la recuperación del planeta. Esta agenda enfrenta poderosos intereses económicos. Comienza una disputa de sentidos en la educación en medio de la discusión de la llamada "nueva normalidad".

Hoy vivimos una encrucijada. Se ha desatado una crisis del modelo económico neoliberal cuyo desenlace está por definirse. Bien podemos caminar hacia una 
transformación, o bien dar un giro hacia atrás, que construya una "normalidad" que sea un maquillaje mal hecho del antiguo orden

Otra vez están juntos el reto de la educación con el reto del desarrollo. Al igual que a principios del siglo XX el fin del orden oligárquico estaba vinculado al fin de la exclusión educativa y el analfabetismo; hoy a principios del siglo XXI, el fin del orden neoliberal está vinculado al fin del modelo educativo que socava el derecho a la educación.

Lo viejo no termina de morir y lo nuevo recién comienza a nacer. El agotamiento del modelo anterior ya había dado signos visibles antes de la pandemia, provocando una oleada de movimientos sociales en varios países de América Latina y de Europa ("Los indignados"). El punto más alto se dio en Chile, donde el movimiento ciudadano puso en jaque al gobierno de Piñeira e incluyó como parte se su agenda nodal la gratuidad de la educación y el fin del endeudamiento estudiantil en la educación superior.

Esta etapa enfrenta en su fase final a un nuevo desafío del siglo XXI: la crisis ambiental que coloca a los seres humanos al filo del precipicio de la destrucción del planeta. El virus del COVID 19 es ocasionado por la crisis ambiental.

Las epidemias emergentes, así como el cambio climático, son antropogénicas, es decir, causadas por las actividades humanas... Una economía global basada en la ilusión del crecimiento ilimitado [...] se traduce en una ilimitada transgresión de los límites del planeta, de los ecosistemas y de las especies. (Vandana Shiva, 2020)

El COVID 19 pone en jaque a toda la humanidad y devela la crudeza de la desigualdad, del atropello a los derechos humanos, de la degradación del medio ambiente, del abandono del bien público, de la corrupción asociada al lucro, etc. Es como si todos los sapos y culebras del orden antes preconizado como ideal de progreso, salieran a la palestra y mostraran su esencia y lado oscuros.

Se derrumba el relato neoliberal. La pandemia pone fin abrupto al crecimiento económico e instala la recesión más grande de la historia mundial desde la primera guerra mundial. Hoy somos testigos y actores de una crisis que muchos analistas califican de sistémica, crisis que vincula recesión económica, daño ambiental profundo, violencia y políticas de segregación y exclusión en diversos lugares del planeta.

La República como constructo ha demostrado su extrema fragilidad, porque la democracia fue carcomida por un modelo económico devastador de derechos e institucionalidad. 
¿Qué lugar ocupa la educación en esta nueva situación? Hay dos dimensiones en la relación de la pandemia con la educación.

En primer lugar, el virus ha desnudado la precariedad a la que fueron sometidas la educación y la salud públicas y la extrema segmentación de la educación. Se ha necesitado una pandemia mundial para entender la importancia de la educación pública como la única manera de asegurar el pleno ejercicio del derecho a la educación por parte de las mayorías. Se hizo evidente la falsedad de las políticas de austeridad en el "gasto" social que, en el caso de la educación nos condujeron a pretender calidad educativa primero con colegios sin servicios y ahora con hogares sin internet, computadora, y a veces, ni siquiera luz. El coronavirus desvistió las miserias de la mercantilización de la educación, de "esa apuesta en la cual el Estado debía desaparecer o minimizarse y dejar que la competencia y el libre mercado hicieran el milagro de la calidad" (Helfer 2020).

En segundo lugar, la pandemia reveló los sinsentidos del modelo educativo. Fue como una especie de terremoto. Las escuelas cerradas y los niños confinados pusieron al sistema educativo en una dimensión desconocida. De golpe y porrazo la realidad no coincidía con los documentos y planes. Era y es equívoco trasladar la acción educativa a la modalidad remota o virtual, como si nada hubiera cambiado. Ya no funciona el mito del "emprendedor". Sería un grave error seguir preconizando la formación de estudiantes competitivos que puedan lograr el "éxito" a costa de su esfuerzo individual y "meritocrático" y al margen de las desigualdades abismales en que viven. El mito se cae cuando vemos a niños subiendo a la cumbre de un cerro para captar línea de internet y compartiendo 2 celulares para 7 estudiantes. Está claro que el emprendedurismo no disuelve la desigualdad.

Otro mito el modelo educativo hoy cuestionado es creer que todos deben aprender lo mismo y de la misma manera. La estandarización y centralización de los contenidos y formas de educar se habían ya demostrado como ineficaces. Con la pandemia parecen absurdas, porque no se puede regular un año totalmente irregular. En él las recetas y plantillas no son replicables y las rúbricas y "semáforos" carecen de sentido, al pretender monitorear en serie procesos educativos que se están reinventando en todas partes. El modelo estandarizado suponía una situación social plana que no existe.

En el marco de una crisis moral del país, en educación asistimos a la puesta en agenda del derecho a la educación y el cuestionamiento, incipiente aún, del lucro y mercantilización de la educación. Siempre más tarde que nuestros países vecinos como Chile, la agenda de fortalecimiento del derecho a la educación y del fortalecimiento de la educación pública, está comenzando a plantearse. Simultá- 
neamente también de manera aún marginal, se comienza a cuestionar el modelo de educación reduccionista, limitada a la formación de habilidades básicas para el mercado de trabajo. Reaparece en los márgenes la utopía de una educación ciudadana, de cara a los retos de la democracia, del equilibrio ambiental, de la convivencia de diversidades.

La crisis educativa tiene también una dimensión epistemológica que cuestiona la manera de entender fragmentariamente el mundo en que vivimos y la manera como se pretende enseñar en las escuelas: con contenidos restrictivos y escasa importancia al arte y a las humanidades, con marginalidad de los llamados temas transversales y con aislamiento frente a los problemas ambientales y del entorno. Frente a ello se requiere una pedagogía crítica que posibilite la comprensión y construcción de un mundo culturalmente diverso con una perspectiva emancipadora.

Otro equívoco que se hace evidente es pensar que el ser humano es independiente de la naturaleza y es el único eje de los procesos pedagógicos. Ya no es posible vivir y tampoco educar al margen de la naturaleza, porque, como dice Edgar Morin, no existimos en el mundo, sino que somos con el mundo. Y si dejamos de lado el mundo ponemos en riesgo nuestra sobrevivencia. La creciente degradación del medio ambiente es producto de la acción humana, de un modo de producción que busca el lucro a costa de la vida y que hoy la pone en peligro. En contraparte, se retoma la necesidad de educar para la sustentabilidad de la vida (Cumbre de la Tierra 1972) y para la construcción de sociedades sustentables, más humanas, más justas, construyendo un sentido compartido de colectivo de seres vivientes que cooperan y no compiten entre sí.

Las alternativas del nuevo orden se enfrentan a fuertes mecanismos de defensa del modelo vigente que sigue manejando los resortes centrales del poder económico y permea la esfera del poder político buscando una "nueva normalidad" que maquille la misma situación de mercantilización, segmentación, desigualdad y lucro en la sociedad, y también en la educación.

Plantear retos para la educación de cara al bicentenario implica postular la transformación de la educación junto con la construcción de un nuevo modelo social y económico inclusivo. Es cada vez más claro que hay que poner en serio debate lo que se está proyectando como "nueva normalidad". Boff plantea que "volver a la normalidad es autocondenarse" porque ese orden "normal" se basa en la "voracidad por un crecimiento ilimitado a costa de la sobreexplotación de la naturaleza y la indiferencia ante la pobreza y la miseria de la gran mayoría de la humanidad producida por ella" (Boff 2020:1). 
La educación no puede replantearse en sí misma. Tiene que hacerlo vinculado a los desafíos de la época de cuestionamiento del orden neoliberal salvaje. Este se encuentra en crisis, al igual que lo estuvo el orden oligárquico hace un siglo. ¿Cuánto tiempo tomará cambiarlo?

Este cuarto momento nos pone de cara a la utopía. "En la historia de la humanidad, las utopías adquieren un valor especial en los momentos de crisis, como un sinónimo de recuperación del rumbo y del sentido de la evolución de la humanidad y de la vida" (Kepowicz 2002: 30). En el caso de la educación, las utopías educativas son fundamentales porque proyectan sentidos y signan el derrotero de la formación de los seres humanos.

\section{Conclusión}

En el Perú hemos transitado de una sociedad oligárquica donde la educación era un privilegio, a un orden neoliberal en el cual el Estado tiene un rol subsidiario y se mercantiliza la educación en lugar de garantizarla. Entre ambos momentos hay un período de reforma donde la educación se expandió como derecho, utopía y canal de movilidad social.

La divergencia entre imaginario educativo incluyente y modelo económico excluyente se impuso finalmente y terminó convirtiendo la utopía republicana en un discurso vacío. En suma, la República como constructo ha demostrado su extrema fragilidad a lo largo del siglo siendo finalmente carcomida por un modelo económico devastador de derechos e institucionalidad.

Nos acercamos al bicentenario en medio de un contexto de crisis sanitaria, humanitaria y civilizatoria que ha puesto en jaque el orden neoliberal. Hoy se vuelve a colocar la justicia social y educativa como asunto nodal y esto sucede al lado de otro punto sustancial de la agenda: la recuperación del planeta. Resolver estos retos es un requisito para hablar con propiedad de "República".

\section{Bibliografía}

ACUeRdo NaCiOnal (2002). Política No. 12. Acceso Universal a una Educación Pública, Gratuita y de Calidad y Promoción y defensa de la Cultura y el deporte, Lima, Consulta 22 mayo 2020 https://www.acuerdonacional.pe/politicas-de-estado-del-acuerdo-nacional/ politicas-de-estado\%E2\%80\%8B/politicas-de-estado-castellano/ii-equidad-y-justiciasocial/12-acceso-universal-a-una-educacion-publica-gratuita-y-de-calidad-y-promocion-y-defensa-de-la-cultura-y-del-deporte/ 
BALARIN, M. (2016). La privatización por defecto y el surgimiento de las escuelas privadas de bajo costo en el Perú. ¿Cuáles son sus consecuencias?, En RASE-Revista de la Asociación de Sociología de la Educación No.9. Consulta 9 setiembre 2020, https://www.researchgate.net/publication/326092937_La_privatizacion_por_defecto_y_el_surgimiento_de_ las_escuelas_privadas_de_bajo_costo_en_el_Peru_Cuales_son_sus_consecuencias

Banco Mundial (2015 a). World Development Report 2015: Mind, Society, and Behavior, World Development Report, Washington, http://documentos.bancomundial.org/ curated/es/645741468339541646/World-development-report-2015-mind-societyand-behavior

BANCO MUNDIAL (2015 b). Informe sobre el Desarrollo, Mente, sociedad y conducta, Washington, Resumen en español, http://pubdocs.worldbank.org/en/210751493925193701/pdf/ Overview-Spanish.pdf

BANCO Mundial (2018). "Aplicación de las ciencias del comportamiento para poner fin a I pobreza y reducir la desigualdad", http://documents.worldbank.org/curated/ en/140621532460617085/pdf/128784-SPANISH-BRI-PUBLIC-eMBeD-BrochureSpanish-Digital.pdf

BeLlo, M. (2018). "Los COAR, la persistencia de un error", Revista TAREA 97 octubre, Lima. https://tarea.org.pe/wp-content/uploads/2018/11/Tarea97_29_Manuel_Bello.pdf

BofF, L. (2020). Volver a la «normalidad» es autocondenarse, Consulta 30 julio 2020, http:// www.servicioskoinonia.org/boff/articulo.php?num $=983$

ETCHICHURY, H. (2015), “La mente, la pobreza y el banco mundial: una perspectiva de derechos humanos", DIALNET: Vol. XIII, N²3, 2015, pp 49-65, https://dialnet.unirioja.es/ descarga/articulo/5502218.pdf

COMISIÓN DE REFORMA DE LA EDUCACIÓN (1970). Reforma de la educación peruana. Informe general. Lima: Ministerio de Educación.

CONSEJO NACIONAL DE EdUCACIÓN (2020). La Educación que queremos para el Perú, Proyecto educativo Nacional 2007-2021, Consulta. 23 julio 2020, http://www.cne.gob.pe/uploads/ proyecto-educativo-nacional/version-pen/pen-oficial.pdf

CORTINA, A. (1999). El quehacer ético. Guía para la educación moral. Lima: Ed. Santillana.

CUENCA, R. (2019) “Explorando las brechas de desigualdad educativa en el Perú". En Revista Mexicana de Investigación Educativa, Vol 24, No. 81, México, Consulta 23 mayo 2020, http:// www.scielo.org.mx/scielo.php?script=sci_arttext\&pid=S1405-66662019000200431

NACIONES UNIDAS (1972) Cumbre de la Tierra, Conferencia Internacional, Estocolmo.

DEGREGORI, C. (1986). "Del mito de Inkarrí al mito del progreso". En Socialismo y participación. No. 36. Diciembre. Lima. Consulta 22 julio 2020, https://www.yumpu.com/es/ document/read/12704968/del-mito-de-inkarri-al-mito-del-progreso-partido-politico- 
Durand, F. (2004). “Los nuevos dueños del Perú", * Quehacer, DESCO, Lima. Consulta 22 agosto 2020, https://www.desco.org.pe/recursos/sites/indice/31/143.pdf

Foro Educativo (1992). La escuela que el Perú necesita. Lima.

Foro EduCATIVo (1994). Ser maestro en el Perú. Reflexiones y propuestas. Lima.

Foro EducATIVo (1992). Bases para un Acuerdo Nacional por la Educación, Lima.

Freire, P. (1970). Pedagogía del oprimido, Tierra Nueva Uruguay. Consulta 22 julio 2020, http://www.servicioskoinonia.org/biblioteca/general/FreirePedagogiadelOprimido.pdf

GramsCl, A. (1972). Notas sobre Maquiavelo, sobre la política y sobre el Estado Moderno, Ed Visión Buenos Aires.

GolemAn, D. La inteligencia emocional, Ed. Kairos, Consulta 3 setiembre 2020, http://www. codajic.org/sites/www.codajic.org/files/Inteligencia\%20Emocional\%20\%20Daniel\%20 Goleman.pdf

GUADALUPE, C.; TWANAMA, W. y CASTRO, M. (2018). La larga noche de la educación peruana: comienza a amanecer, Documento de discusión CIUP, Lima. Consulta, 30 agosto 2020, https://repositorio.up.edu.pe/bitstream/handle/11354/2184/DD1806. pdf? sequence $=6 \&$ isAllowed $=y$

HeLfER, G. (2020). "Y las escuelas no eran chifas", Foro Educativo, Lima, Consulta 3 de agosto 2020, http://foroeducativo.org/2020/04/23/y-las-escuelas-no-eran-chifas/

KEPOWICZ, B. (2002), “Utopías y educación”, Revista Reencuentro, núm. 34, Universidad Autónoma, México, Consulta 23 agosto 2020, https://www.redalyc.org/pdf/340/34003403.pdf MALPICA, C. (1984). Los dueños del Perú. Lima: Ed. Peisa.

MARIÁTEGUI, J. C. (1928). 7 ensayos de interpretación de la realidad peruana. Lima: Editorial Amauta.

MARIÁTEGUI, J. C. (1970). Temas de educación. Lima: Editorial Amauta.

MERLIN, N. (2017). Colonización de la subjetividad. Ecuador: Ed. Letra viva.

MINISTERIO DE EDUCACION (2003). Ley General de Educación 28044, Lima.

Ministerio de EduCACION (2002). Puertas Abiertas, Consulta Nacional de Educación, Lima

MIRANDA Y PACHECO (2020). "Financiamiento de la educación en el Perú", en El financiamiento educativo en América Latina, DOSSIER No.52 de Propuesta Educativa, Flacso, Argentina. Consulta 18 junio 2020, http://propuestaeducativa.flacso.org.ar/wp-content/ uploads/2020/05/PropuestaEducativa52-2.pdf

MORIN, E. (1999). Los siete saberes necesarios para la educación del futuro, Orealc, UNESCO, París. Consulta 10 junio 2020, http://www.ideassonline.org/public/pdf/LosSieteSaberesNecesariosParaLaEdudelFuturo.pdf

NeIRA, H. (2019). La anomia (1980-2018). De unos cuantos, a plaga social, arriba y abajo, Lima, Instituto de Gobierno y Gestión Pública, Univ. San Martín de Porres. Consulta: 
20 junio 2020 https://gobiernoygestionpublica.edu.pe/iggp/2019/10/24/la-anomia1980-2018-de-unos-cuantos-a-plaga-social-arriba-y-abajo/

PAlomino, E. (1992). Educación peruana: historia, análisis y propuestas. Lima: Pro Educación. PIKETTY, T. (2019). Capital e ideología, Ed Planeta, Barcelona, traducción de Daniel Fuentes. Proyecto: Diagnóstico General de la Educación 1993, Lima.

Tovar, T. (1985). Reforma de la Educación: balance y perspectivas. Lima: DESCO.

Tovar, T. (1994). Política educativa y Rol del Magisterio, en Ser Maestro en el Perú, Foro Educativo, Lima.

TovaR, T. (2019). Apunte sobre la reforma educativa, en Quehacer № 2, Velasco, un balance a 50 años del gobierno revolucionario, DESCO, Lima, Consulta 12 julio 2020, http:// revistaquehacer.pe/n2\#apunte-sobre-la-reforma-educativa, Consulta: 10 julio 2020

Tovar, T. (2020 a) "Vuelta de tuerca: Educación pública y apuesta por la vida", En Revista Educaccion, Lima, Consulta: 2 setiembre 2020, https://www.educaccionperu.org/ vuelta-de-tuerca-educacion-publica-y-apuesta-por-la-vida/?fbclid=IwAROVCcUnymj ntGq9HtHw0zvmpbmZ7lehy264Vv1zck5bSnWgT005FYJ3PZE,

Tovar, T. (2020 b) “Banco Mundial: encubriendo la desigualdad”, Ed. lamula, Lima, Consulta 20 agosto 2020, https://teresatovars.lamula.pe/2020/01/07/banco-mundial-encubriendola-desigualdad/teresatovar/?fbclid=IwAR1_3dDGJxilGrpIWQrfu82aXQAV9w8JCCtDFU GiO-R5Hqoo1ZfKdtJVH3k,

Tovar, T. et al. (1989). Ser Maestro. Condiciones del trabajo docente en el Perú. UNESCO/ OREALC Santiago de Chile.

SALAZAR, A. (1975). La educación del hombre nuevo: la reforma educativa peruana. Buenos Aires: Paidós. Consulta 12 mayo 2020, https://sisbib.unmsm.edu.pe/bibvirtual/libros/2006/ educ_hombre/contenido.htm,

SANDEL, J. (2020). La tiranía del mérito. ¿Qué ha sido del bien común?, Traducción de Albino Santos Mosquera, Debate Libros, Consulta: 22 julio 2020, https://www.casadellibro. com/ebook-la-tirania-del-merito-ebook/9788418006357/11682374,

VANDANA, S. (2020). “Un virus, la humanidad y la tierra”, 11 abril, Consulta: 20 julio 2020, https://www.elsaltodiario.com/el-rumor-de-las-multitudes/un-virus-la-humanidady-la-tierra

Vergara, A. (2018). Ciudadanos sin República. Lima: Ed. Planeta.

Young, M. (1964). El triunfo de la meritocracia 1870-2034 ensayo sobre la educación y la igualdad, Ed. Teknos Madrid. 